\title{
Vitreomacular Traction Post Intravitreal Bevacizumab for Age Related Macular Degeneration
}

\section{Okonkwo N. Ogugua ${ }^{1}$, Hassan O. Adekunle ${ }^{1}$, Gyasi E. Micheal ${ }^{2}$, Oluyadi B. Fatai ${ }^{3}$, Ogunro Adunola ${ }^{3}$, Oderinlo Olufemi ${ }^{1}$, Ulaikere Mildred ${ }^{3}$, Harriman Ayodele ${ }^{3}$}

\author{
${ }^{1}$ Eye Foundation Retina Institute, Lagos, Nigeria \\ ${ }^{2}$ Saint Thomas Eye Hospital, Accra, Ghana \\ ${ }^{3}$ Eye Foundation Hospital, Lagos, Nigeria \\ Email: ${ }^{\star}$ o_okonkwo@yahoo.com
}

How to cite this paper: Ogugua, O.N., Adekunle, H.O., Micheal, G.E., Fatai, O.B., Adunola, O., Olufemi, O., Mildred, U. and Ayodele, H. (2017) Vitreomacular Traction Post Intravitreal Bevacizumab for Age Related Macular Degeneration. Open Journal of Ophthalmology, 7, 138-144.

https://doi.org/10.4236/ojoph.2017.72019

Received: March 10, 2017

Accepted: May 28, 2017

Published: May 31, 2017

Copyright $\odot 2017$ by authors and Scientific Research Publishing Inc. This work is licensed under the Creative Commons Attribution International License (CC BY 4.0).

http://creativecommons.org/licenses/by/4.0/

\begin{abstract}
Purpose: To report the significant worsening of Vitreomacular Traction (VMT), following the intravitreal injection of Bevacizumab (Avastin) in an Age Related Macular Degeneration (AMD) eye; thereby raising the awareness of this possibility. Method: Retrospective observational case report. Results: After 3 monthly doses of intravitreal injection of $1.25 \mathrm{mg} / 0.05 \mathrm{cc}$ bevacizumab for treatment of AMD, a post injection OCT revealed the presence of VMT and an increased central macular thickness (CMT) by additional 268 microns compared to pre injection levels. Conclusion: Worsening of VMT and increase in CMT following injection of intravitreal drugs can occur. This VMT worsening effect of intravitreal injections is under recognized. It demands greater attention since it is seen with a new common route of ocular drug delivery and may be responsible for cases of pharmacological failure.
\end{abstract}

\section{Keywords}

Vitreomacular Traction, Vitreomacular Adhesion, Intravitreal Injection, Optical Coherence Tomography, Avastin, Age Related Macular Degeneration

\section{Introduction}

There is evidence to support the clinical association of age related macular degeneration (AMD) and vitreomacular adhesion (VMA) or vitreomacular traction (VMT); also this association occurs commonly [1] [2] [3]. The Sub macular Surgery Trials (SST) investigating the surgical removal of choroidal neovacular membranes (CNVM) reported an unusual number of elderly patients, to have an 
intraoperative finding of attached posterior hyaloid [4]. Published data suggests that it is common to find VMA/VMT occurring in AMD eyes when compared to age matched non-AMD control eyes [5] [6]. This association perhaps is more common with exudative AMD when compared to non-exudative AMD eyes. VMT has been suspected to play a role in the pathogenesis of AMD, alongside other well-known and understood mechanisms. VMT adversely worsens AMD possibly due to the tractional forces that are exerted on the macular inducing inflammation or other mechanisms [6]. Lastly, there is a suggestion that tractional forces of the VMT may antagonize the effect of intravitreal anti VEGF therapy and cause pharmacological treatment failure and resistance [7].

\section{Case Report}

A 69-year-old female who had been attending routine clinic visits for the monitoring of non-exudative AMD for 8 years noticed a reduction in her right eye vision. At presentation 8 years ago, her unaided visual acuity was OD 6/24 and OS $6 / 60$. With a hyperopic correction (OD $+2.00 \mathrm{DS}$ and OS $+2.50 \mathrm{DS})$ she improved to $6 / 5$ in both eyes. There were early cataracts in both eyes, but the rest of the anterior segment was normal. The significant finding upon dilated funduscopy was the presence of few scattered drusen in the macular area in both eyes.

By the sixth year of her follow up, she was noted to have significant increase in the number of drusen, which were now soft and confluent. There was also an increase in the degree of cataract, more in the right eye. Cataract surgery was contemplated and discussed. Her vision progressively deteriorated in both eyes, but was worse in the right eye.

At her most recent clinic visit she could now see OD 6/12 and OS 6/9 (with her correction). This visual decline was as a result of the combined effect of cataract and deteriorating macular degenerative changes, which had converted to a wet AMD in the OD.

Investigation: Fundus photograph: revealed presence of multiple soft confluent drusen in both eyes, significantly more in the right eye (Figure 1(a) and Figure 1(b)).

OCT: OD: Dome shaped foveal elevation, significant sub retinafluid accumulation with increased central macular thickness (CMT) to 610 microns. There were degenerative changes in the outer retina. The vitreous was seen to have detached and above the dome shaped elevation (Figure 2).

At the diagnosis of wet AMD and cataract in the OD, monthly intravitreal anti VEGF (Vascular Endothelial Growth Factor) was initiated as treatment. At this time, a right eye posterior vitreous separation was thought to have occurred based on the initial OCT findings. A regimen of three monthly bevacizumab (Avastin) was given in her OD. Her vision remained unchanged at the end of 3 months.

Post the 3 monthly intravitreal Avastin injection, a repeat OCT OD revealed a classic pattern of VMT, but now with a further increase in CMT by 268 microns to new levels of 878 microns. This was much higher than the pre injection CMT 


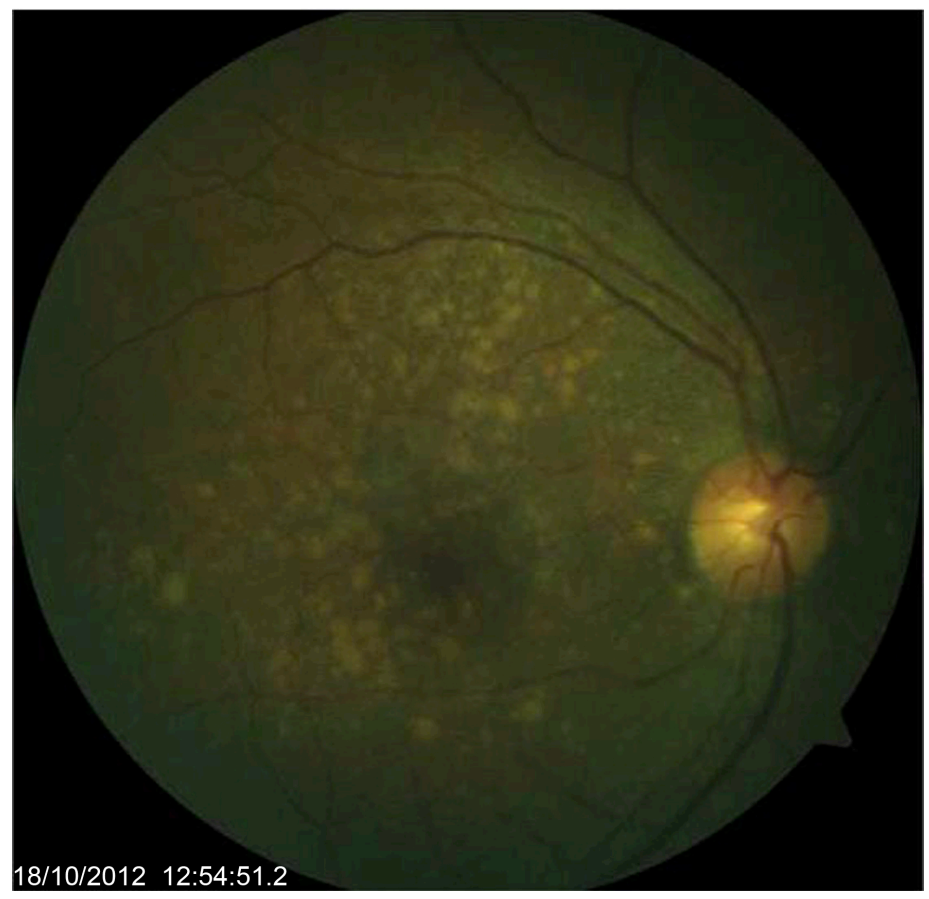

(a)

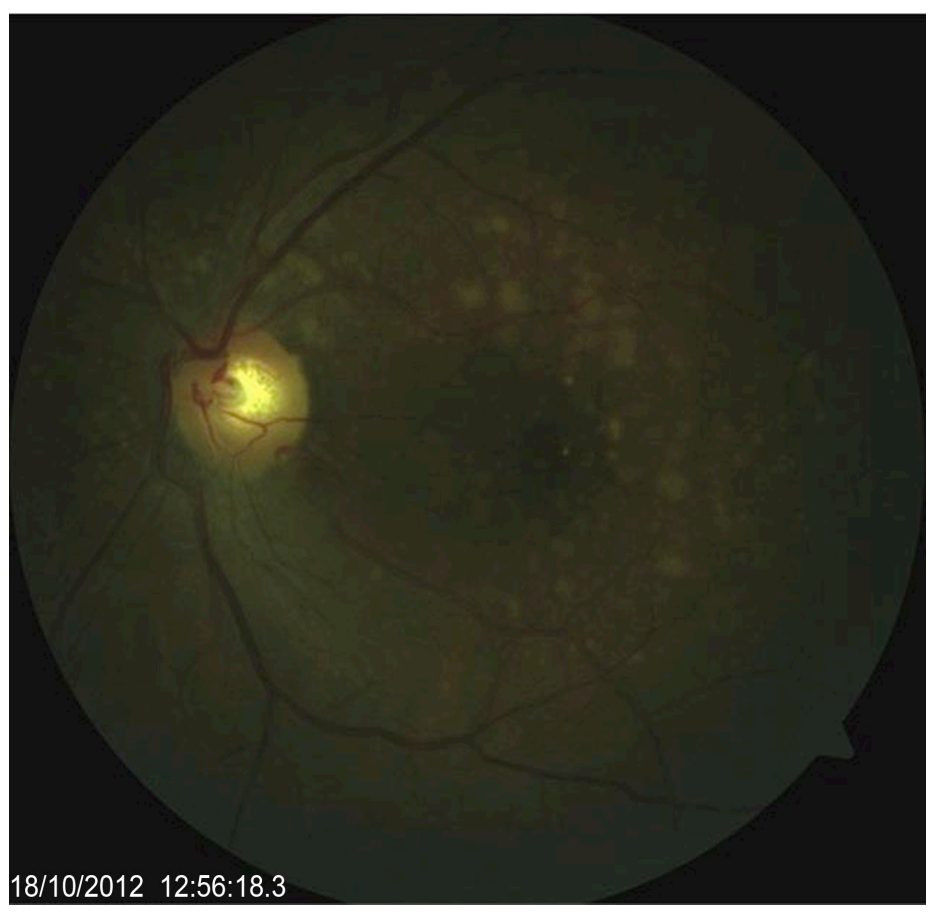

(b)

Figure 1. (a) \& (b) Fundus picture of the right eye and left eyes showing multiple confluent drusen more in the right eye (AMD OD and AMD OS Jpg pics).

(Figure 3). The left eye OCT remained unchanged.

No further intravitreal injection of Avastin was given after the third dose. As she was followed without treatment, a repeat OCT showed a decrease in CMT, but with VMT still present (Figure 4). 


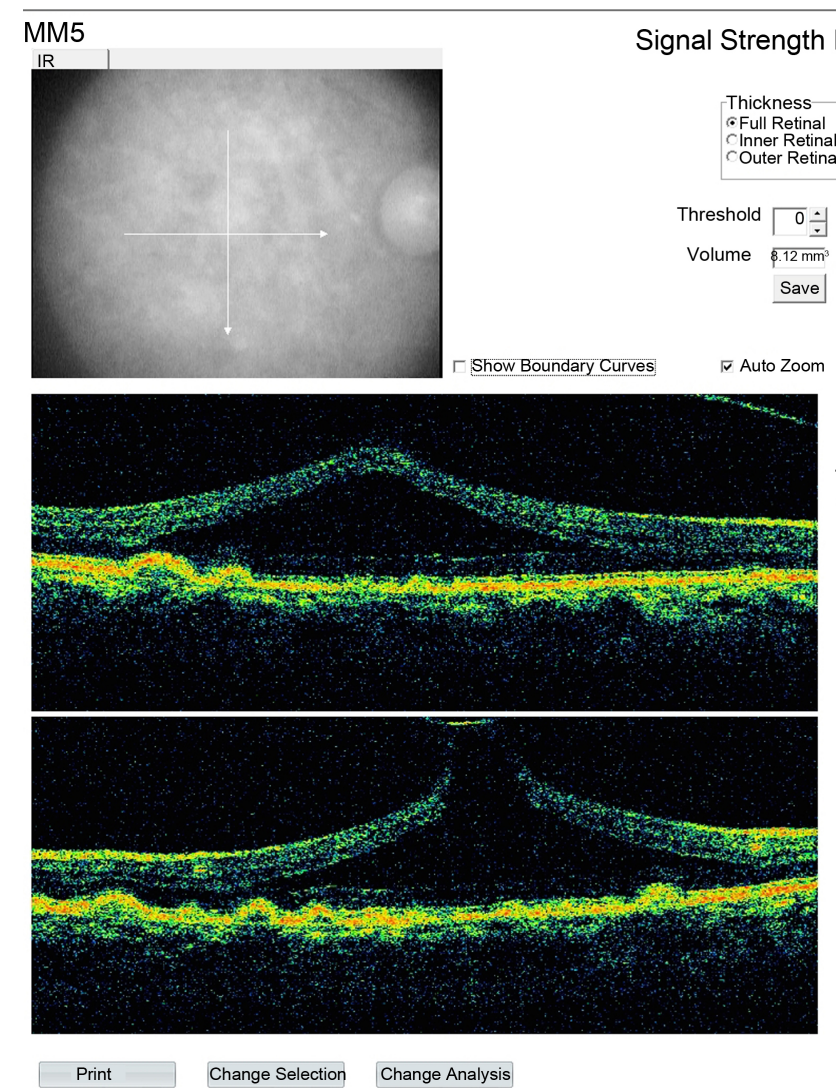

Right/OD
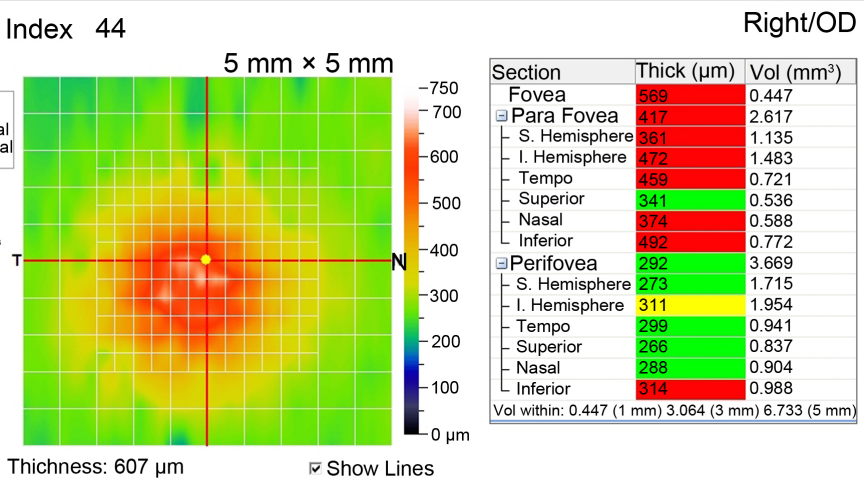

$(-0.41,0.00) \mathrm{mm}$
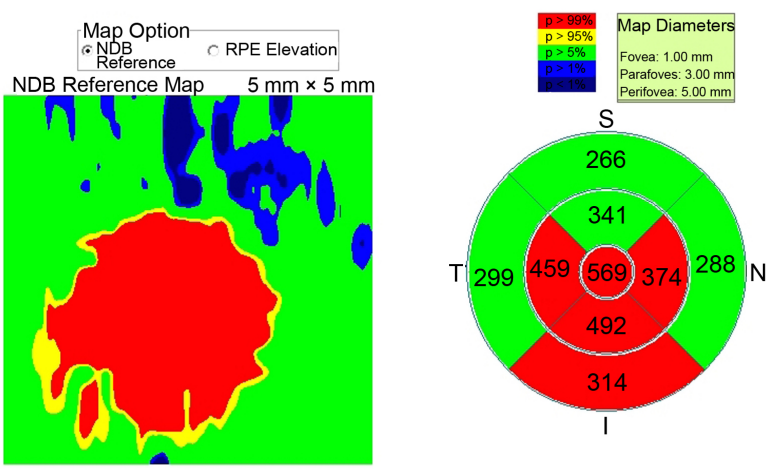

Figure 2. OCT of the right eye. Note the right eye dome shaped elevation of the neurosensory retina and detached posterior hyaloid from the retina (AMD 3 Jpg pic).

Right/OD

MM5 OU Report

Left/OS
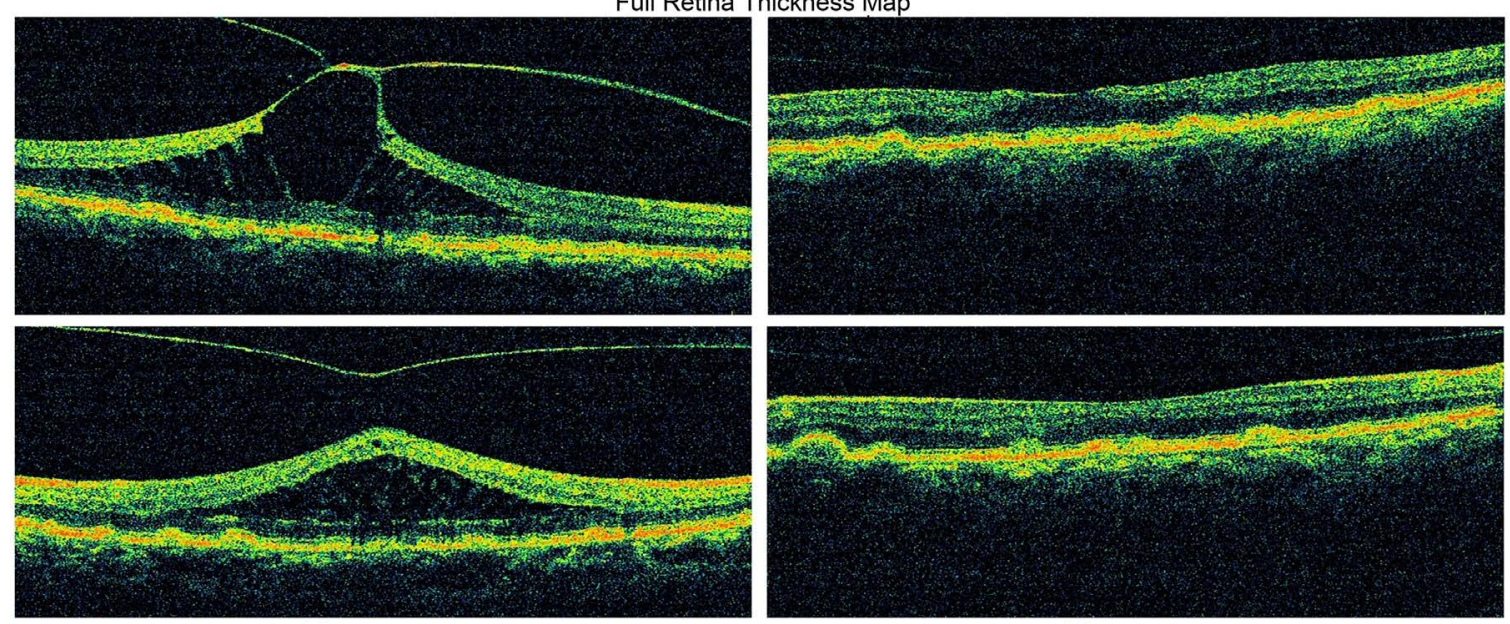

Exam Date: $31 / 01 / 2013, \mathrm{SSI}=52.0$

Exam Date: $01 / 31 / 2013, \mathrm{SSI}=50.7$

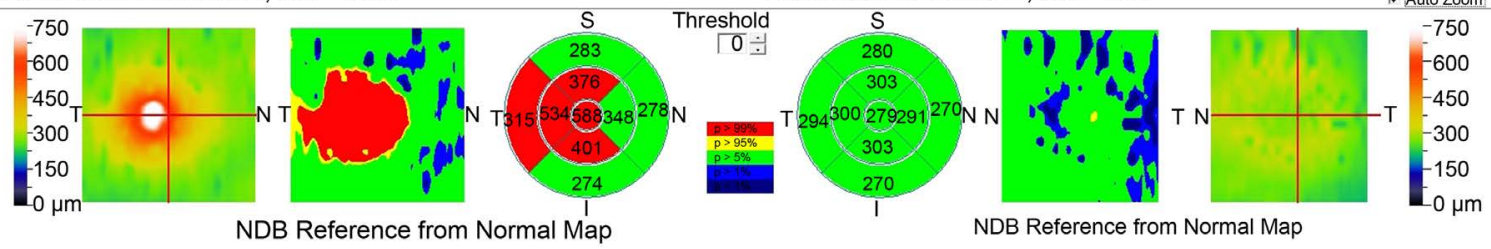

Figure 3. The OCT of the right eye post X 3 monthly doses of intravitreal avastin showing an increase in the central macular thickness to 878 and a classical pattern of the vitreomacular traction now evident in the central macular area. The left eye appears unchanged (AMD 4Jpg pic). 


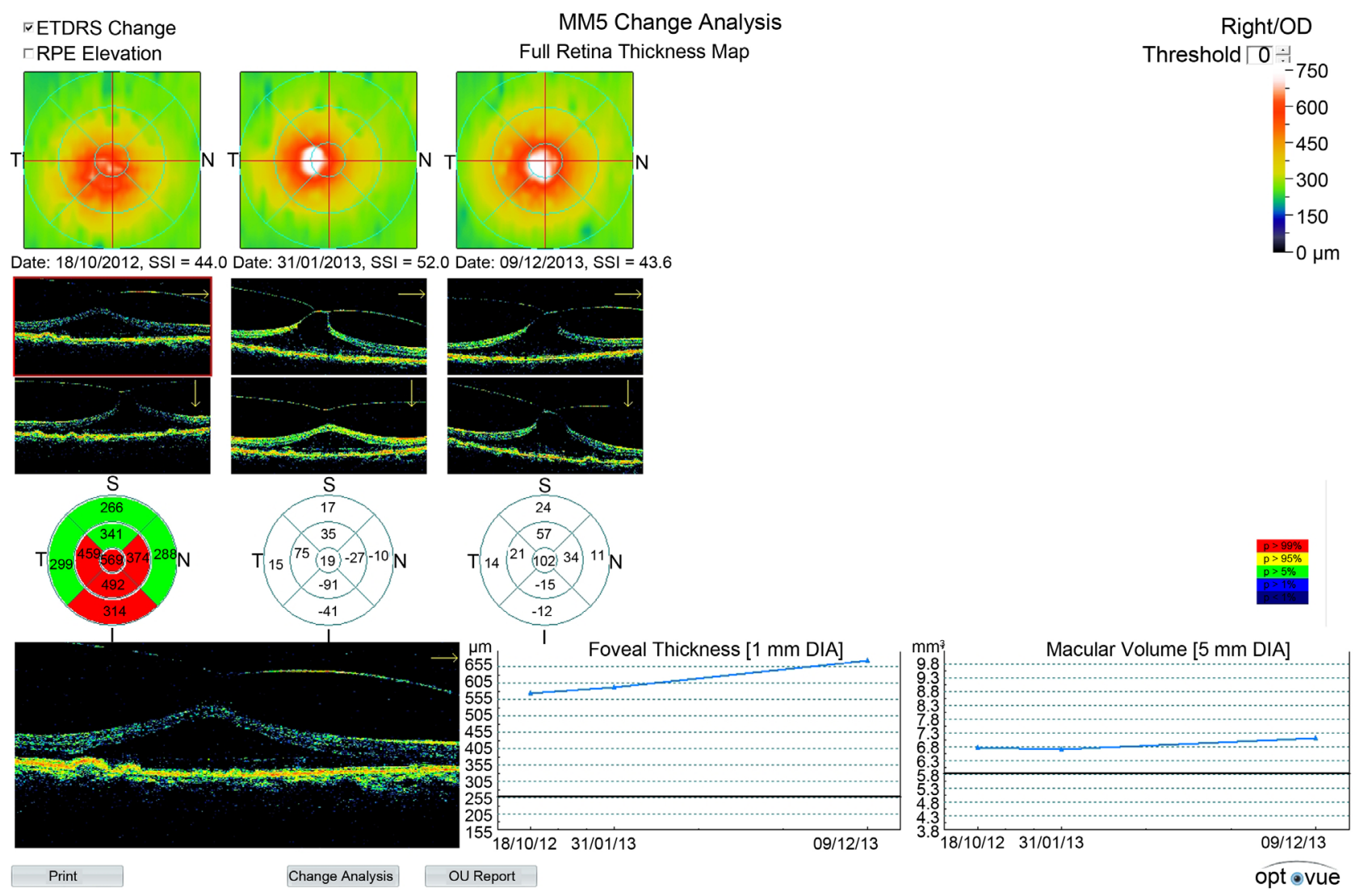

Figure 4. The three sequential OCT images of the right eye showing first the preoperative values, middle immediate post X 3 monthly doses of avastin and lastly the reduction in central foveal thickness back to pre injection levels after cessation of further injections (AMD 5 Jpg pic).

\section{Discussion}

Intravitreal anti VEGF is established as the treatment of choice for wet AMD and its effectiveness and safety has been validated by several randomized trials. However this complication of intravitreal injections in AMD with VMT is not often discussed. Since VMT and VMA are common associations of AMD it is a potentially important complication and its incidence may be under estimated.

We propose a mechanical theory for this increase in CMT following intravitreal anti VEGF injection. This increase in CMT in this case presented was induced by the injection of the intravitreal Avastin, resulting in increasing vitreous mobility and vitreous traction. This worsened the initially missed VMT. The fact that cessation of the intravitreal drug resulted in a return of the CMT to pre injection level, further suggests that administration of the intravitreal drug was directly responsible for the worsening VMT and increase in CMT.

This case suggests that an often used route for administration of ocular pharmacotherapy in the treatment of AMD (ieintravitreal anti VEGF) may cause worsening of VMT when there is pre existing VMT or VMA. This finding is probably under recognized following intravitreal anti-VEGF use for the treatment of AMD. Considering that VMT is a well-recognized association of AMD, this observation is worthy of emphasis. This is especially so as VMT on its own 
may worsen AMD and ultimately result in anti VEGF treatment failure [5] [7].

This vitreomacular tractional effect of the intravitreal injection of pharmacotherapy could hold true in all the other medical retina conditions in which intravitreal injection of drugs is done in a situation where there is pre existing VMA or VMT. This will include such conditions as diabetic macular edema, retina vein occlusion and some uveitic conditions (in which intravitreal injection of steroids is required) [8] [9].

Worsening or formation of VMT in situation of AMD is a possible mechanism, which has been under recognized, responsible for treatment failures in cases of exudative AMD refractory to anti-VEGF therapy. This should be borne in mind, and intravitreal injections should be given with a possibility of worsening or increased CMT in the category of patients with AMD and VMT.

\section{Conclusion}

To conclude, Anti-VEGF drug injection in the setting of recognized VMA or VMT should be undertaken with caution. Prognosis may be guarded and a worsening of VMT may occur. More attention ought to be paid to vitreous examination in patients to be commenced on intravitreal pharmacotherapy than that is currently been done by retina physicians. This case report reflects this point. A more detailed evaluation of the vitreomacular attachments across a wider or broader area of the macular to better understand the pattern of vitreomacular attachment using the OCT and perhaps the B scan in some cases is advisable, at least before initiating anti-VEGF therapy.

\section{References}

[1] Simpson, A.R., Petrarca, R. and Jackson, T.L. (2012) Vitreomacular Adhesion and Neovascular Age-Related Macular Degeneration. Survey of Ophthalmology, 57,498509. https://doi.org/10.1016/j.survophthal.2012.01.011

[2] Krebs, I., Glittenberg, C., Zeiler, F. and Binder, S. (2011) Spectral Domain Optical Coherence Tomography for Higher Precision in the Evaluation of Vitreoretinal Adhesions in Exudative Age-Related Macular Degeneration. British Journal of Ophthalmology, 95, 1415-1418. https://doi.org/10.1136/bjo.2010.192385

[3] Lee, S.J., Lee, C.S. and Koh, H.J. (2009) Posterior Vitreomacular Adhesion and Risk of Exudative Age-Related Macular Degeneration: Paired Eye Study. American Journal of Ophthalmology, 147, 621-626. https://doi.org/10.1016/j.ajo.2008.10.003

[4] Lambert, H.M., Capone, A., Aaberg, T.M., Sterberg, P., Mandell, B.A. and Lopez, P.F. (1992) Surgical Excision of Subfovealneovascular Membranes in Age-Related Macular Degeneration. American Journal of Ophthalmology, 113, 257-262. https://doi.org/10.1016/S0002-9394(14)71576-4

[5] Mojana, F., Cheng, L. and Freeman, W.R. (2008) The Role of Abnormal Vitreomacular Adhesion in Age Related Macular Degeneration: Spectral Optical Coherence Tomography and Surgical Results. American Journal of Ophthalmology, 148, 218 227. https://doi.org/10.1016/j.ajo.2008.04.027

[6] Krebs, I., Brannath, W., Gittenberg, C., Zeiler, F., et al. (2007) Posterior Vitreomacular Adhesion: A Potential Risk Factor for Exudative Age-Related Macular Degeneration? American Journal of Ophthalmology, 144, 741-746. 
https://doi.org/10.1016/j.ajo.2007.07.024

[7] Schulze, S., Hoerle, S., Mennel, S. and Kroll, P. (2008) Vitreomacular Traction and Exudative Age Related Macular Degeneration. Acta Ophthalmologica, 86, 470-481. https://doi.org/10.1111/j.1755-3768.2008.01210.x

[8] Degenring, R.F. and Jonas, J.B. (2003) Intravitreal Injection of Triamcinolone Acetonide as Treatment for Chronic Uveitis. British Journal of Ophthalmology, 87, 361. https://doi.org/10.1136/bjo.87.3.361

[9] Sugita, S. (2007) Intravitreal Anti-Inflammatory Treatment for Uveitis. British Journal of Ophthalmology, 91, 135-138.

Submit or recommend next manuscript to SCIRP and we will provide best service for you:

Accepting pre-submission inquiries through Email, Facebook, LinkedIn, Twitter, etc. A wide selection of journals (inclusive of 9 subjects, more than 200 journals)

Providing 24-hour high-quality service

User-friendly online submission system

Fair and swift peer-review system

Efficient typesetting and proofreading procedure

Display of the result of downloads and visits, as well as the number of cited articles Maximum dissemination of your research work

Submit your manuscript at: http://papersubmission.scirp.org/

Or contact ojoph@scirp.org 